\title{
De la técnica a la hermenéutica
}

\author{
María Antonia González
}

$\mathrm{H}$

ace casi cincuenta años que Heidegger escribió "La pregunta por la técnica", ${ }^{1}$ y si en ese entonces era ya difícil cuestionar a la técnica, hoy en día, después de tantas transformaciones de las condiciones técnicas, tecnológicas y científicas, esa tarea se vislumbra como una empresa que linda, desde algunas perspectivas, con la imposibilidad. Pues ha sido en gran medida gracias a la técnica que hemos logrado transformar ese mundo que se nos presentaba como hostil y amenazador, en un mundo humano, en el que ahora tenemos ante todo la seguridad frente a la impetuosidad e intempestividad de la naturaleza, un logro que la humanidad ha fraguado a sangre y fuego.

En efecto, no es sencillo cuestionar a la técnica sin caer en una especie de apología del "mundo natural" o en un "ecologismo", además mesiánico, que continúa viendo lo no-humano como "objeto de museo". No es sencillo cuestionar a la técnica sin caer en falacias de corte esencialista o naturalista, o apostando por éticas que se ven irremediablemente seducidas por imperativos categóricos y que se pretenden universales y necesarias.

Es cierto que es factible llevar a cabo interpretaciones de los textos de Heidegger sobre la técnica ${ }^{2}$ bajo una mirada o bien ecológica o bien escatológica, puesto que podemos encontrar en dichos textos argumentaciones que de

${ }^{1}$ Martin Heidegger, "La pregunta por la técnica", en Conferencias y artículos. Trad. de Eustaquio Barjau. Barcelona, Ediciones del Serbal, 1994. (Colección Odós)

${ }^{2}$ Además del texto citado "La pregunta por la técnica", queremos mencionar que otras significativas reflexiones sobre técnica y ciencia se encuentran en M. Heidegger, "Ciencia y meditación" y "Construir, habitar, pensar", en Conferencias y artículos; $\mathrm{M}$. Heidegger, "La vuelta (Die Kehre)", en Filosofía, ciencia y técnica. Trad. de Francisco Soler. Santiago de Chile, Editorial Universitaria, 1997, y M. Heidegger, "La época de la imagen del mundo", en Caminos de bosque. Trad. de Helena Cortés y Arturo Leyte, Madrid, Alianza, 1997. 
hecho tienen ese tono. Mas pretendemos aquí ensayar una interpretación que vaya más allá de esa mirada, para situarse exclusivamente en el tema del pensar, es decir, abordar a la técnica como un peligro para el pensar-puesto que consideramos que justo ahí se inserta la importancia de la reflexión heideggeriana-, desvinculándola así de toda problemática de destrucción y decadencia del mundo.

En ese sentido, el problema que aquí nos ocupa es dilucidar desde dónde podemos cuestionar a la técnica. Y más allá, hemos de preguntarnos si sigue siendo válida la crítica heideggeriana, o más que válida, si es aún viable; una viabilidad que, creemos, se encuentra al llevar el cuestionamiento de Heidegger hacia la hermenéutica. Así, en lo que sigue expondremos una lectura de "La pregunta por la técnica" que apueste, pese a todo, por una cierta viabilidad de la crítica heideggeriana.

Para ello, comenzaremos por aclarar que en el texto citado, Heidegger no se pregunta por la técnica, sino por su esencia. En consecuencia, enfocaremos nuestro análisis en eso que Heidegger llama "la esencia de la técnica", la cual no es para él nada técnico, es decir, no tiene nada que ver con el despliegue tecnológico que experimentamos cotidianamente.

La esencia de la técnica, antes que ver con la técnica, tiene que ver con el ser; ésta, afirma Heidegger, descansa en esa estructura llamada "fondo fijo acumulado" o "estructura de emplazamiento", el Gestell.

Gestell como época en la que el ser se envía destinalmente como olvido y como fondo fijo acumulado. Época de la modernidad, época del dominio técnico del mundo. Mas recordemos que época no quiere decir para Heidegger un periodo determinado de la historia de la humanidad; modernidad no es pues el siglo XVII ni el XVIII, modernidad es un modo de acaecer el ser y es en esta modernidad donde se da el dominio técnico del mundo. Dominio que no hace referencia a la Revolución Industrial, sino al esplendor de la razón instrumental y de la metafísica.

Técnica, modernidad y metafísica se entrelazan en el pensamiento heideggeriano para en ellas ubicar el peligro supremo, como lo llama Heidegger en "La pregunta por la técnica”. Para poder pensar el peligro, debemos primero analizar brevemente estas tres figuras.

De acuerdo con Heidegger, la metafísica se ha caracterizado por un constante y puntual olvido de la finitud a favor de una racionalidad que crea estructuras fijas y trascendentales que predeterminan al pensar, que lo anquilosan en las formas "válidas" de conocimiento.

Algunos de los rasgos fundamentales de la metafísica son explicados por Heidegger con mayor puntualidad en la "Época de la imagen del mundo". Afirma inicialmente que nos encontramos viviendo en lo que él llama la época de la imagen del mundo, que a su vez coincide con lo que es la modernidad. 
La época de la imagen del mundo comprende, o gira, de acuerdo al autor de Ser y tiempo, en torno a tres ejes: la idea del sujeto como centro y fundamento, la ciencia como criterio único de verdad y de progreso y la consecuente tecnificación del mundo.

La metafísica del sujeto entendido como centro y fundamento de todo lo existente es gestada en el pensamiento cartesiano, en el cual quedamos reducidos a ser únicamente razón y sede de toda certeza. Una razón tan poderosa que funda un antropocentrismo desde el cual el sujeto decide sobre todos los entes. El sujeto así entendido se convierte en un sujeto trascendental, teórico, a partir del cual todo se explica y todo se entiende. Tirano del pensar, déspota del ente -asevera Heidegger-, del ser y de la vida que desde sus estrechos límites pretende reinar en todo el universo. Tal es el lugar que el "yo" del hombre adquiere en la modernidad racionalista.

Sujeto que no necesita del mundo para ser, que se afirma con insolente independencia, que busca afanosamente "la verdad" absoluta e inamovible. La razón rige y domina todo el horizonte del quehacer humano, reduciéndonos a ser sujetos racionales que se representan un mundo como objeto, como imagen, como sistema. Lo real deviene re-presentación del sujeto para entonces poder afirmarlo en su certeza y verdad. Para Heidegger, esto significó que la filosofía asumió el modelo de la racionalidad técnico-científica.

Progreso y superación resuenan en la modernidad, eco de un pensar encadenado a un telos determinado por la razón y justificado en un archai apriorísticamente.

En este sentido, es el humanismo el fenómeno básico de la modernidad. ${ }^{3}$ Para Heidegger, es precisamente el humanismo la condición de posibilidad de asegurarnos nuestro lugar en el mundo y garantizarnos el dominio de todo lo otro, asignándonos el papel de sujeto como sede de la evidencia, del conocimiento y de la certeza. Una vez concluida la realización de una antropología metafísica, es decir, habiéndonos definido como sujetos racionales, se gesta una idea de humanización como racionalización y dominio técnico del mundo.

Heidegger ha señalado reiteradamente que la metafísica, en su modo de darse epocalmente, se ha caracterizado por ser un pensamiento dirigido hacia un telos y hacia una estructura del ser como fundamento. En ese sentido, afirma que la metafísica se ha esforzado por describir una estructura del ser que califica como verdadera. El ser, convertido en un ente, es el presupuesto último y primero de la fundamentación de la metafísica, la cual implica lo que él llama el olvido del ser en favor del ente, la metafísica es pues un modo de darse el ser: como olvido.

${ }^{3}$ Cf. M. Heidegger, Carta sobre el humanismo. México, Peña Hermanos, 1998. 
Heidegger ubicará en el modo en el que se da la técnica moderna la develación del olvido del ser. Preguntemos entonces, junto con Heidegger, ¿qué es la técnica?

La modernidad está cortada por la idea de progreso y la fe en él, todo está convocado a producir un provecho tangible, práctico, inmediato. En este modo de relación con el mundo se lleva a cabo una tecnificación del mismo, tecnificación que es, para Heidegger, la realización de la metafísica, en tanto sólo es posible si nos pensamos como sujetos racionales dominadores de un mundo representado.

La técnica en la modernidad funda una organización total, un sistema totalizador en el que el mundo, el objeto, no es sino un producto técnico producido por el hombre dominador, ordenador del mundo.

Técnica es entonces olvido del ser, olvido del ser en favor de los entes. Técnica que organiza un orden del mundo en el que el ser del ente es determinado por la voluntad del sujeto. Es en este estado de cosas, desde la perspectiva de Heidegger, donde yace la posibilidad de un peligro radical para el hombre: el peligro de convertirse en nada más que un ente junto con todos los demás entes. Si el sujeto de la modernidad es aquel que demanda siempre más de la naturaleza a través de la técnica, llega entonces un momento -la culminación de la metafísica- en el que los papeles se invierten: de tanto demandar el hombre se convierte en el demandado, como afirma Heidegger en "La pregunta por la técnica".

La técnica es un provocar que solicita sin cesar que el mundo esté siempre dispuesto y disponible, siempre ahí presente como objeto presto a ser provocado, interpelado. Técnica como imposición, como alteración de nuestra relación con el mundo y de nosotros mismos. Época del Gestell.

Desde el Gestell entendemos al mundo como un "fondo fijo acumulado" al que se le exige estar puesto o dispuesto para la técnica, para la explotación teórica o instrumental que lleva a cabo un sujeto que no es más que un demandante compulsivo cuya exigencia no termina nunca. Gestell es un modo de acaecer el ser en la técnica.

Si la metafísica y su culminación en la técnica nos convierten en ese ente demandante y a su vez demandado, parece que para salvarnos sólo podemos arriesgarnos a pensar al ser ya no como fundamento sino como evento, como Ereignis apunta Heidegger. ¿Qué quiere decir esto?

En "La pregunta por la técnica" Heidegger retoma las palabras de Hölderlin y anuncia: "Pero donde está el peligro, crece también lo que salva". 4

\footnotetext{
${ }^{4}$ M. Heidegger, "La pregunta por la técnica", en op. cit., p. 30.
} 
Es justo esta frase la que nos permitirá construir un puente que nos lleve de la técnica a la hermenéutica, entendida la primera como el peligro y la segunda como lo que salva. ¿En qué sentido podemos afirmar esto?

Comencemos por el peligro. Heidegger afirma en "La vuelta (Die Kehre)" que el peligro es el Gestell, es decir, el peligro es justa y precisamente el ser mismo que se ha enviado destinalmente como olvido. El peligro no es el despliegue tecnológico ni la destrucción del planeta, sino el ser. Asegura Heidegger en "La vuelta" que "Todo intento del computar, morfológica y psicológicamente, lo real, como caída y pérdida, fatalidad y catástrofe, como decadencia, es solamente conducta técnica". ${ }^{5}$

Si el peligro es el ser, es igualmente peligro la apertura del ser o época del ser en la que estamos caídos, arrojados; ese horizonte en y desde el cual existimos. Un horizonte caracterizado por la estructura metafísica que describimos. Un horizonte en el que nos hemos definido como sujeto y sólo como sujeto y en el que el mundo ha sido definido por ese sujeto como objeto y sólo como objeto. Nuestra relación con el mundo ha sido, no tanto modificada, sino establecida en estos términos, y el comportamiento técnico respecto al mundo y respecto a nosotros mismos sólo se puede dar partiendo de aquella concepción metafísica. Es decir, el peligro emerge y se hace presente desde nuestro pensar porque nosotros somos antes que nada apertura al ser.

En ese sentido, el peligro se cierne desde nuestro pensar, ya que éste se ha reducido a ser la razón del racionalismo, que ha buscado la perfección del sistema y el anquilosamiento en el concepto.

Hemos insertado entonces al mundo, a nosotros y a nuestra relación con él en un esquema metafísico de olvido del ser y de dominio del ente, esquema técnico por ello, porque en el acto creativo, poiético, en el traer de la nada al ser, creamos sólo en tanto sujetos racionales y creamos, por tanto, objetos asequibles al conocimiento, y sólo eso.

El peligro no está en que la técnica represente una falta de creatividad, una enajenación o una alienación, puesto que quién negaría que ha sido precisamente la técnica la que en gran medida nos ha permitido desplegar nuestras posibilidades creativas más allá de lo creíble. El peligro está en que esa creatividad, en cierta medida, ha transitado por un solo camino, el de la metafísica, provocando que lo desocultado, lo traído a la luz mediante el acto poiético sea no más que un objeto disponible para su explotación. Una creatividad que ha impulsado una visión del mundo en tanto que objeto de explotación y una visión de nosotros en tanto que sujeto explotador.

El peligro, creemos, está en la univocidad, en pretender un único método como garantía de la verdad, en el anquilosamiento, en la reducción del mun-

${ }^{5}$ M. Heidegger, "La vuelta (Die Kehre)", en op. cit., p. 193. 
do a conceptos unívocos. El peligro, pues, es nuestro pensar en tanto reducido a cálculo, ya que al ser él el propiciador del desocultamiento ha desocultado el mundo como fondo fijo acumulado. Y consideramos, siguiendo a Heidegger, que eso constituye un peligro no porque no deba de haber técnica moderna, sino porque ésta ha cerrado las puertas de prácticamente todo otro pensar arrojándolo hacia la marginación y el descrédito.

En otras palabras, que el pensar haya establecido un único modo de pensar como cierto y verdadero ha llevado como consecuencia el dejar de lado otros modos de crear y de desocultar. El peligro no está en que impulsemos el desarrollo de la técnica, sino en que nos dediquemos exclusivamente a esto y que nuestra relación con el mundo empiece y termine en ello. Hay que abrir un espacio libre para otro modo de desocultamiento, para otro tipo de creación que no excluya a la técnica pero que tampoco la encumbre a un punto tal que haga desaparecer lo demás, por ejemplo, a las artes que han sido relegadas a objeto de museo y de las cuales se afirma no poseen ninguna verdad que sea susceptible de continuar impulsando el "progreso".

Es al interior del peligro donde crece lo que salva, puesto que es nuestro pensar y nuestras posibilidades poiéticas las que son capaces de crear otra relación con el mundo, otra apertura al ser. Lo que salva es un giro o vuelta en el peligro mismo para que éste se convierta en una fuente de multiplicidad y no de univocidad.

Salvar significa, escribe Heidegger en "La vuelta", "soltar, liberar, libertar, cuidar, albergar, tomar en custodia, resguardar". 6 Salvar es entonces una vuelta en el peligro que libera nuestro pensar de las cadenas que se ha impuesto en la persecución del conocimiento y de la verdad. Salvar es cuidar y resguardar al ser a través de un pensar más abarcante que el racionalista y que piense al ser ya no como fundamento sino como acontecer e historicidad.

¿Cómo pensar al ser desde su acontecer, cómo pensar al ser como acontecer? El único sitio en el cual el ser puede darse como acaecer, es, según Heidegger, el lenguaje; por ello el pensar que ha de pensar al ser, deberá pensar al lenguaje. Pensar al lenguaje es pensar al ser y con ello pensarnos también a nosotros, puesto que somos apertura al ser y lo somos en tanto somos lenguaje.

Lenguaje es para Heidegger creación, poiésis, advenimiento y fundación del ser por la palabra. Lenguaje como potencia creadora, constructora, sitio de aparición del ser. Lenguaje como interpretación ya siempre inacabada, lenguaje como hermenéutica que es capaz de interpretar la palabra sin agotarla, sin reducirla a una sola estructura.

${ }^{6}$ Ibid., p. 188. 
En ese sentido, podemos afirmar que la fundación de una hermenéutica ontológica, en sentido heideggeriano, parte primero de un pensar al ser y segundo de una crítica a la modernidad, a la metafísica y a la técnica; y por inicio de cuentas asume que uno de los rasgos básicos al interior de sus lineamientos implica postularse como un pensamiento que carece de fundamento en términos metafísicos.

La hermenéutica que se puede desprender del pensamiento heideggeriano renuncia a pensar al ser en términos metafísicos de estructuras estables, de fundamentos eternos. Apuesta principalmente por un cuestionamiento de los modos de legitimación del ser y del conocer que la metafísica ha erigido, por una puesta en cuestión -que no es lo mismo que negación- de sus valores y hasta de sus fundamentos.

Un saber hermenéutico pretendería ir más allá de la técnica, pero no como una superación que implicaría la anulación de todo pensar metafísico, sino que desde el fondo del Gestell ha de surgir un modo distinto de pensar, que no excluyera a la técnica, puesto que es junto y a partir de ella desde donde se puede plantear la posibilidad de abrirnos a otra experiencia del ser, a otro modo de relacionarnos con el mundo, técnico y no técnico a la vez.

La hermenéutica, así entendida, es un modo de filosofar que asume la finitud de la existencia y piensa al ser como evento para experimentarlo como libertad y como abismo, puesto que no se agota en una definición según categorías y conceptos.

Sólo porque el ser se da como evento, como ausencia de fundamento, se puede hablar de múltiples interpretaciones, de múltiples maneras de ver y relacionarnos con la realidad, de multivocidad en vez de univocidad. Interpretaciones, perspectivas, que son históricas, siempre cambiantes, no definitivas ni definitorias, laberinto infinito y pluridimensional de perspectivas.

Desde un pensar hermenéutico podemos afirmar que la existencia es libre, porque no está determinada a perseguir un telos, porque no tiene fundamento. Libertad que se traduce en historicidad, en multiplicidad de interpretaciones, en multiplicidad de verdades, porque, en última instancia, el ser también es multiforme y el despliegue de la técnica y su peligro no son absolutos ni definitivos.

La hermenéutica que está implícita a lo largo de todo el pensamiento heideggeriano se presenta como no definitoria, ni perentoria, ni absoluta ni trascendental; sino que, por el contrario, es un saber siempre distinto, siempre cambiable, siempre móvil y modificable, de ahí que al margen de la racionalidad instrumental sea posible abrirnos a distintas experiencias.

Esta hermenéutica se asume finita, se sabe frágil y contingente, sabe bien que cada una de sus interpretaciones juega libremente a inventarse y que ninguna se afirma como última, que no puede haber una interpretación 
que se erija como conocimiento consumado; al contrario, apuesta por una infinitud de interpretaciones porque cada una es sólo una posibilidad entre otras muchas.

Al pensar al ser como evento ya siempre interpretado históricamente, la hermenéutica afirma el devenir, la movilidad de sus interpretaciones, el ir y venir, el vaivén en la creación de sentidos. Justamente crear sentidos y abrirnos a ellos es lo que Heidegger denomina "espíritu" ${ }^{7}$ y por tanto diferencia ontológica. Pensando al ser como acontecer, la hermenéutica sabe que la experiencia de la interpretación es un proceso inacabado, incompleto, pero nunca por ello fallido, incorrecto o imperfecto.

Si para Heidegger no hay una estructura verdadera del ser porque éste es acontecer, entonces lo que se presenta es una pérdida de credibilidad en cualquier forma de legitimación absoluta -como se ha postulado la razón instrumental-, puesto que no hay un fondo originario ni una verdad suprasensible, no hay un mundo verdadero ni parámetros absolutos a partir de los cuáles se pueda medir; sino que, por el contrario, todo es suceder.

Y en este suceder se inserta la hermenéutica que reconoce que sus interpretaciones son aconteceres libres, puesto que ya no hay más una estructura verdadera que sea fuente tanto de certezas en el plano cognoscitivo, como de normas en el terreno moral, no hay leyes ni valores "objetivos" ni mucho menos "universales" ni con carácter de imperativo.

Es, en este sentido, como la hermenéutica no pretende ser un camino del pensar que imponga imperativos y exigencias de universalidad. Así, esta hermenéutica es un carácter diverso que anticipa otro modo posible de ser y de pensar, mas no un modo único o categórico, por el contrario, representa una posibilidad más, susceptible de ser abierta en medio de otras muchas, incluyendo la técnica, sabiendo de antemano que ninguna de ellas sería mejor o peor, sino simplemente diferente. Este es un pensamiento que lleva implícita la conciencia de la disolución de los modelos.

Desde dicha disolución apostamos, siguiendo a Heidegger, por una hermenéutica que sea un pensar incluyente y no excluyente como el metafísico, que sea creativo desde y como lenguaje, tan creativo como para ser capaz de transformar una vez más nuestra existencia y el mundo que nos rodea.

${ }^{7}$ Cf. M. Heidegger, Introducción a la metafísica. Trad. de Ángela Ackermann Pilári. Barcelona, Gedisa, 1997. 